work of GPs and psychiatrists.

I myself am a GP in the NHS. I care for ten addicts. I see them each week, sometimes twice weekly. Of course I receive no payment other than the normal capitation fee of £6 per annum.

As an organization we agree with most of the statements in the DHSS Report, but feel it is too narrow, insufficiently clear and contains too many vague words, phrases, subjective judgments and contradictions. It does nothing to dispel and much to reinforce the myths and misunderstandings that abound in our society about drug addicts. It makes no attempt to assess the country's drug problems as a whole or to assess the black market and the many connections between crime and addiction. We feel that such an assessment is vital before there can be successful treatment and rehabilitation.

The Report points out important problems but does not discuss them. It describes the hopeless inadequacy of the present system, yet goes on to recommend more of the same. It points out that only a minute proportion of addicts attend clinics, but then discusses the problem as though these addicts are the whole problem. It makes no attempt to discuss why the vast majority of addicts (perhaps as many as $95^{\circ}$ per cent) refuse to go to clinics, and it reveals a belief that we cannot share in the effectiveness of committees. It considers neither the needs of stable addicts nor how to help other addicts to become stable. It does not question current prescribing policies, though these have aroused much controversy and dissent. It makes suggestions for the extension of the present licensing system in a way which we believe would cause a considerable increase in crime and distress throughout the community. It fails to discuss the fact that informed opinion is deeply divided about the way in which Britain tackles her drug problem, or the fact that there are totally different, though equally serious, points of view. It makes no criticism of the clinics but much criticism of independent doctors. It makes no mention of the fact that many people believe that it is with GPs at least as much with clinics, that solutions are likely to be found. It tends to invoke planning without any clear statement of what the planning concerns. Overall, it omits so much that a proper balance of emphasis is made impossible.

\section{Our proposals:}

1. There should be an important inquiry into the whole problem of drugs in our society. Until that is done we should be aware of the fact that we do not know what we are trying to control.

2. Boundaries for clinics should be adjusted so that no addict is deprived of a clinic, should he wish to attend one.

3. The prescribing of 'Diconal' should be restricted, but further prescribing restrictions should await greater knowledge.

4. Encouragement and payment should be given to GPs to look after addicts on their lists, and information and training should be easily available to them.

5. Co-operation between independent doctors and clinics should be encouraged by all possible means.

TESSA HARE Secretary

Association of Independent Doctors in Addiction

13 Devonshire Place, London WI

(See also news items on page 195.)

\section{Where are the resources needed the most?}

\section{DeAR Sirs}

Dr Brooks (Bulletin, August 1983, 7, 148) raises important points with implications for the nature and practice of psychiatry in general and community psychiatry in particular. We are preparing a further paper along these lines. Perhaps, however, we could make one or two specific comments.

Establishing the Mental Health Advice Centre gave a community psychiatric base in Lewisham which had previously had none. Monitoring the centre's work from the start soon drew attention to the needs which were being met and those which were not. This led to the development of a Crisis Team based at the Centre whose work has been described (Tufnell $e t a l$ ) and which deals largely with severely ill individuals of the type Dr Brooks mentions. A Rehabilitation Team has been set up at the Centre which will be concerned with psychotic patients and this will be reported upon.

We can assure Dr Brooks that the Mental Health Advice Centre has had catalytic effects on cognate services in Lewisham, including the psychogeriatric service, which is now the responsibility of other consultants whose number is now increased by the first Professor of Psychogeriatrics in the United Kingdom, one of whose tasks will be to improve services in Lewisham.

D. I. BROUGH

N. BOURAS

Lewisham Psychiatric Research Unit

J. P. WATSON

Mental Health Advice Centre

19 Handen Road, London SE12

REFERENCE

TufNell, G., Bouras, N., Brough, D. I., \& Watson, J. P. (1983) Crisis intervention in practice: A three-year study. British Journal of Medical Psychology (submitted for publication).

\section{Insanity and genius}

DeAr SiRs

It would appear your correspondents (Bulletin, March $1983,7,55)$ are not familiar with the literature on the 